\title{
BMJ Open Gut feelings in the diagnostic process of Spanish GPs: a focus group study
}

\author{
Bernardino Oliva, ${ }^{1}$ Sebastià March, ${ }^{2}$ Cristina Gadea, ${ }^{3}$ Erik Stolper, ${ }^{4,5}$ \\ Magdalena Esteva ${ }^{2}$
}

To cite: Oliva B, March S, Gadea C, et al. Gut feelings in the diagnostic process of Spanish GPs: a focus group study. BMJ Open 2016:6:e12847.

doi:10.1136/bmjopen-2016012847

- Prepublication history for this paper is available online. To view these files please visit the journal online (http://dx.doi.org/10.1136/ bmjopen-2016-012847).

Received 27 May 2016 Revised 25 October 2016 Accepted 27 October 2016

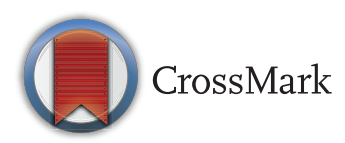

For numbered affiliations see end of article.

Correspondence to Dr Bernardino Oliva; boliva@ ibsalut.caib.es

\section{ABSTRACT}

Objectives: The gut feelings of doctors can act as triggers and modulators of the diagnostic process. This study explored the existence, significance, determinants and triggers of gut feelings among Spanish general practitioners.

Design: Qualitative study using focus groups. Thematic content analysis.

Setting: Primary healthcare centres in Majorca (Spain).

Participants: 20 purposively sampled general practitioners working in Majorca.

Results: General practitioners were aware of the existence of gut feelings in their diagnostic reasoning process and recognised 2 kinds of gut feelings: a sense of alarm and a sense of reassurance. A previous physician-patient relationship and the physician's experience had a strong perceived influence on the appearance of gut feelings. The physicians attached great significance to gut feelings, and considered them as a characteristic of the primary care working style and as a tool available in their diagnostic process. The physicians thought that the notion of gut feelings and their relevance can be transmitted to students and trainees. They tended to follow their gut feelings, although they were not sure of their accuracy.

Conclusions: Spanish general practitioners in our study recognise the presence and role of gut feelings in their diagnostic reasoning process. Future research should examine the diagnostic accuracy of gut feelings and how to teach about gut feelings in the training of general practitioners.

\section{BACKGROUND}

Psychological research on clinical reasoning shows that general practitioners (GPs) and doctors in general use two strategies for diagnosis: problem solving and decision-making. ${ }^{1}$ In problem solving, GPs confirm or refute a working hypothesis by considering the symptoms and signs. This model incorporates pattern recognition, in which signs or clues that fit a specific condition enable doctors to make the correct diagnosis. In decisionmaking, the likelihood that a diagnosis is true depends on the initial probability, based

\section{Strengths and limitations of this study}

- This is the first study to examine diagnostic gut feelings in a Spanish-speaking area.

- The qualitative approach used here provides information about the existence, significance, determinants and triggers of gut feelings among Spanish general practitioners.

- Our study sample was heterogeneous in age, experience, gender and location of practice, and the consensus was wide and rapidly achieved.

- The analysis was performed by three researchers to assure the validity of the results.

on the disease's known prevalence or the clinician's subjective assessment of the probability of a disease, and the application of available scientific evidence. The decisionmaking approach is used in evidence-based medicine, is analogous to Bayes' theorem, and commonly employs notions such as likelihood ratios, decision trees and diagnostic algorithms. Despite its theoretical superiority, the decision-making model has potential biases and is less used in clinical practice. ${ }^{23}$

There are other ways of approaching diagnosis in the fields of medicine and psychology. ${ }^{4}$ In some models, intuition-defined as the outcome of highly personalised, knowledge-based, automatic non-analytical processes-is a characteristic of advanced learning processes. ${ }^{5}{ }^{6}$ Psychological theories postulate dual processes as the simultaneous existence of two forms of knowing and understanding: a rational and analytical process that is controlled, explicit and slow; and an implicit, associative, intuitive and rapid non-analytical process. ${ }^{7}$ Kahneman and Klein $^{8}$ discuss these approaches. They agree that an environment of high validity (they use medicine as an example) and adequate chances for learning the regularities of that environment (by means of practice and feedback) are necessary conditions for the development of skilled intuitions. Cognitive neuroscientists showed that emotions are actively involved in decision-making. ${ }^{9}$ 
The so-called gut feelings (GFs) are related to the previously exposed methods used in the diagnostic reasoning process. A GF may be described as a 'useful warning light, which suddenly lights up to announce that there is something unusual'. ${ }^{10}$ There are expressions with similar meanings in other languages, ${ }^{11}$ and there are references to GFs in fields such as nursing, ${ }^{12} 13$ diagnosis of cancer and serious diseases in primary and specialised care,${ }^{14-16}$ cardiology, ${ }^{17}$ paediatrics ${ }^{18} 19$ and emergency care. ${ }^{20}$ Researchers have previously studied GFs among family physicians in the Netherlands, Belgium, France and the UK. ${ }^{20-24}$

Studies in the Netherlands, Belgium and France showed that there are two types of GFs. ${ }^{22}{ }^{23} \mathrm{~A}$ 'sense of alarm' is a feeling that something 'does not add up' in a particular patient, and this initiates the diagnostic process and makes the GP concerned about a possible serious outcome. A 'sense of reassurance' means that the GP feels sure about the prognosis, even without knowing the precise diagnosis. The 'Gut Feeling Questionnaire' is a validated tool used to determine the presence or absence of GFs in the diagnostic reasoning process of GPs. ${ }^{25}$

The aim of this study was to explore the existence, significance, determinants and triggers of GFs among Spanish GPs. We used a study design similar to the previous Dutch researchers to allow direct comparison of the results.

\section{METHODS}

Our work focuses on opinions and feelings, so we chose a qualitative approach. ${ }^{26}$ GFs can be difficult to characterise, because personal experience has a major effect, and there has been little research on GFs in Spanish-speaking countries. All the researchers of the present study have previous training in qualitative research. We used the focus group approach over individual interviews to take advantage of the interactions between members of the focus group as a tool to stimulate individual discourses. ${ }^{26} 27$ We used purposive sampling to recruit participants to achieve a representative distribution of the factors we wanted to study, such as experience, gender, dedication to GP traineeship, and rural or non-rural practice location. All selected GPs worked for the Majorca Primary Care Department.

Previous research indicated that clinical experience seemed to be a major determinant for GFs. Thus, we separated experienced GPs (more than 10 years of experience beyond residence) from less experienced GPs. ${ }^{21}$ A 10-year cut-off point was selected according to the 10-year rule. ${ }^{28}$ We contacted 12 GPs in each group by telephone or mail, and sent written confirmations after their acceptance to participate.

No relevant information on the topic of discussion was released to reduce bias, and none of the GPs was remunerated for their collaboration. Focus groups were organised in the Majorcan primary care practices that were more geographically accessible to the participants in each group. The day before the second group was scheduled to meet, there was a fire in the health centre. Thus, four of the GPs did not attend the group, as they thought it was suspended. BO, SM and ME organised the meetings and acted as moderators and observers. We prepared a written scenario in advance (box 1) to introduce the topic of GFs at the beginning of the group

\section{Box 1 Gut feelings focus group script}

The aim of this study is to gather information about how the diagnostic process works in primary care. You were trained as doctors to make diagnostic decisions through questions, explorations and algorithms; that is, rational decision-making. That part is known. However, we do know that when making decisions, doctors also consider other things. Let us say that sometimes there are certain feelings and previous experiences that alert us. In the English language medical literature, we talk about 'gut feelings'.

1. What can you tell us about gut feelings?

2. Have you ever previously felt something like a gut feeling?

3. How would you describe it? What do you feel?

4. What would you call them?

5. How do we view these gut feelings?

6. Do you follow gut feelings? What makes you listen to them or not?

7. What triggers these feelings?

8. Are there any symptoms, diseases, types of people, days or situations in which you are more likely to have gut feelings?

9. Do you think gut feelings are related to professional experience? To knowledge (patient or medical)? To gender?

10. Do gut feelings depend on the type of consultation (by appointment vs emergencies), time (normal consultation vs off-hours) or location (rural vs urban)?

11. (If there was no mention of the two types of gut feelings) Research shows a distinction between gut feelings that provide a sense of alarm and a sense of reassurance. What do you think? Do you recognise both types? Do you think such a distinction is useful?

12. Have you ever had feelings of unwarranted security?

13. Could this be taught to trainees or students? How?

14. What relevance do you give to these feelings in the context of primary care?

After the first group, we added:

1. Do you pay attention to the gut feelings of patients, relatives or other healthcare professionals?

After the second group, we added:

1. Do you also have gut feelings in non-face-to-face consultations (by telephone or email)? 
meeting, and to assure that all issues were discussed during the meeting. We then let the GPs talk about their experiences. The researchers, acting as moderators and observers, compared their notes about each meeting after it ended. All points of interest that were prepared in the script were discussed in the first group. An issue was raised during the first group regarding GFs in nurses, patients and relatives, so this was added for the second group; another issue regarding GFs in non face-to-face consultations was raised in the second group, and this was added to the third group. Oral acceptance for participation and audio recording was obtained from each of the participants after introduction of the objectives of the focus groups. The focus groups were audio recorded and then transcribed. The duration of the meetings was $60-70 \mathrm{~min}$.

After the second group, we decided there were not enough GP trainers. We wanted GP trainers and young GPs to be well represented in our groups to discuss the teaching of GFs. Thus, we organised a group of GPs who were trainers for at least 4 years (a complete training period) and GPs who had recently completed their specialty training. After analysis of the third group, we agreed that no relevant new information was detected and considered that the information obtained had reached saturation. Table 1 shows the characteristics of the GPs who attended the focus groups. There were physicians from seven regions of Spain and from three different Spanish-speaking countries.

BO, SM and CG performed a thematic analysis of the transcripts immediately after the first focus group. ${ }^{26} 29$ The researchers individually selected quotes related to the research questions from the transcripts and assigned codes to them. The coding was mainly deductive, based on previous research, although it also allowed debate and the use of new categories. ${ }^{21}{ }^{22}$ This analysis employed the TAMS Analyzer software. Then a meeting was held to discuss the quotes and the codes that were used. Agreement was reached on the quotes, codes and certain categories in which the codes were included. In cases of disagreement, ME and ES made the decision.

\section{RESULTS}

We obtained 59 codes after analysis and coding of the transcripts. We grouped these codes into 13 first-level categories and 4 second-level categories: GFs existence and characteristics, influencing factors, consequences and significance. Table 2 shows the resulting code tree.

\section{Presence and characteristics of GFs}

The GPs in our study recognised that GFs had a role in the diagnostic process, and that GFs led them to make decisions that were not entirely scientific. They describe GFs as something that makes them feel concerned about a patient, without any objective evidence.

There must be something that leads us to make decisions with no basis or foundation. There must be something. This can't be something that is generated spontaneously. (FG1/9)

A hunch, a feeling, it's something you think with no clinical suspicion, with no hypothesis. There's something that "doesn't fit" in this patient. Something that can't be answered. If someone were to ask you why something doesn't "add up", you wouldn't even dare to tell them why. (FG2/10)

GPs use GFs, in addition to the scientific diagnostic reasoning process that they learnt during their years at medical school and specialty training. GFs emerge during the diagnosis process, and are influenced by the GP's personal knowledge of patients, clinical skills and previous experiences.

I carry out my scientific procedure - reason for the visit, history, the interview - and perform the physical examination. If I think I have to order tests, then I do, but sometimes, something that tells you that...(FG3/20)

Many GPs repeatedly used the word 'corazonada' (literally, 'heart feeling'), which is defined by the 'Diccionario de Uso del Español' $\left(2^{\mathrm{a}} \mathrm{Ed}\right)$ as a 'vague belief that something happy or unhappy is going to happen'. The GPs frequently depicted their GFs as related to light, with expressions that refer to enlightenment, a bulb, a lantern or a star.

\section{Table 1 Characteristics of enrolled GPs}

\begin{tabular}{lllll}
\hline & Group 1 & Group 2 & Group 3 \\
\hline Number of participants & 9 & 4 & 7 & 20 \\
Female & 5 & 2 & 5 & 9 \\
Male & 4 & 2 & 2 & 11 \\
Experience $>10$ years & 9 & 0 & 5 & 11 \\
Experience $<10$ years & 0 & 4 & 10.3 & 9 \\
Years of experience (mean) & 30.1 & 7.8 & 3 & 18.7 \\
Number of GP trainers & 4 & 1 & 7 & 5 \\
Rural practice & 3 & 3 & 6 & 1 \\
Urban practice & 6 & & &
\end{tabular}


Table 2 Code tree

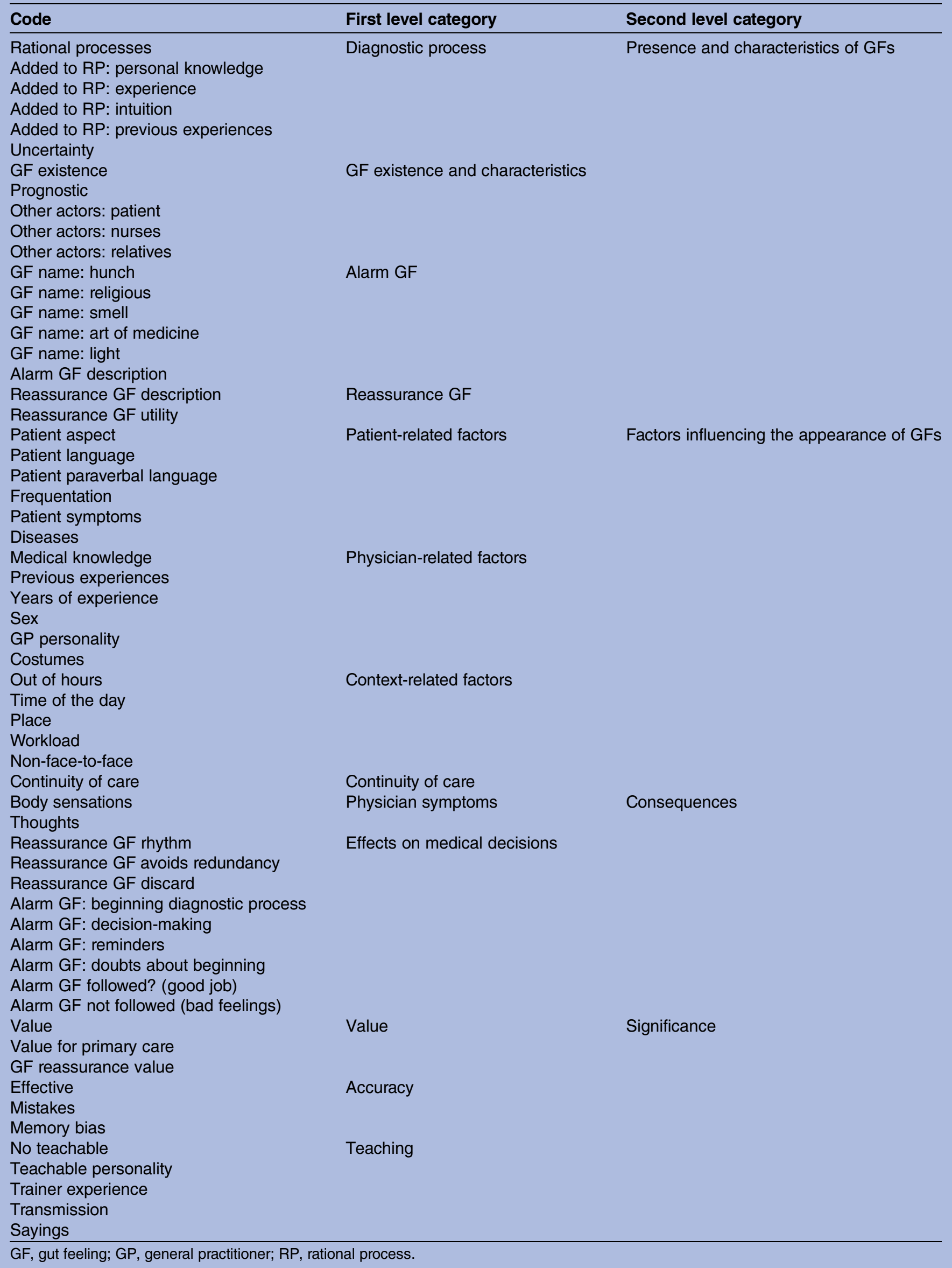


I don't know, you see it clearly. I don't know why, but a little light comes on here that tells you something's wrong and it's going to get worse. (FG2/12)

They also mentioned expressions related to religion (a Marian apparition, a guardian angel) and the art of medicine.

I don't know if it was a hunch, but I always think that the Virgin Mary appeared to me that day. (FG2/2)

Nobody explained to me what the art of medicine was, but it reminds me of this. (FG3/18)

The interviewed Spanish GPs distinguished two kinds of GFs: a sense of alarm and a sense of reassurance. The sense of alarm appears when something 'does not add up', so the GP has the feeling that-even without a clear diagnosis - a patient is or will become seriously ill.

A completely normal analysis. The physical examination is completely normal, she has an ultrasound scan from a week ago that is completely normal, and yet I have the feeling this lady is progressively deteriorating. (FG3/20)

A sense of reassurance is when the GP, even in the presence of symptoms that may suggest a serious condition, has the feeling that nothing serious will happen.

Suppose you see a patient with a cough, a temperature, and side pain. Well, any medical student already knows what the patient has, doesn't he? Well, you examine the patient because there is a medical routine you must follow, but you very often say, "I know they don't have pneumonia, I know they don't have it.” (FG1/2)

The GPs in our study attached great value to the sense of reassurance provided by GFs. They said they perceived reassurance more often than a sense of alarm. This sense of reassurance allows them to quickly discriminate potentially mild from serious diseases, and helps them cope with their daily workload.

And I think it's more this feeling than most of the others. You have a stronger feeling that this is right in twenty patients. On the other hand, with one or two, you find yourself saying, "Let's see what's up". The feeling of reassurance you have is fairly high. We work in uncertainty every day, and to be able to have this feeling of reassurance and to go home and rest easy...(FG2/13)

The Spanish GPs in our study regarded GFs as being more related to prognosis (the severity of a patient's condition) than to an exact diagnosis.

The idea is, not so much making a diagnosis, but being able to discern whether the patient might have something serious or not. (FG1/6)

GPs also recognise the existence of GFs in other health professionals who care for their patients. They pay attention to nurses' GFs, and give more credibility to more experienced nurses.

I also believe very much in a nurse's feelings or intuition, who very often tells you "That patient, I don't know what they have, but they don't look right", and then I quickly take care of the patient. (FG2/13)

The GPs also mentioned that patients and their relatives also have GFs that could influence their own feelings and decisions.

If there's a person who is in his fifties, and one day he gets up and says he feels dizzy, and his wife, who has known him for ages, says "It's the first time in his life he's had dizziness", then you're going to attach importance to that, and it's going to awaken that gut feeling in you. (FG3/19)

\section{Factors that influence appearance of GFs}

Numerous factors are linked to the onset of GFs, and these factors are related to the patient, the physician, the context in which the consultation occurs and the existence of a previous doctor-patient relationship.

\section{Patient-related factors}

The GPs in our study mentioned the external appearance of a patient, and the patient's gestures and paraverbal language as triggers for their GFs.

I think sometimes it's not the verbal language, it's the tone of voice they have. The paraverbal language of the body, which I suppose is not done consciously, but you must interpret. And it gives you certain information. (FG2/11)

Use of health services is another factor related to GFs in GPs. Patients who visit doctors less frequently are more likely to elicit a sense of alarm in the GP. Even the number of active episodes in the electronic medical record may have an influence.

There are patients who hardly ever come to see the doctor. And, well, when they come with an appointment and they mention, "the fact is I don't feel too good", you have the feeling that they must be ill, because they rarely come, and when they do come, it's because something's wrong. (FG2/13)

When a patient presents with diffuse symptoms, such as thoracic or abdominal pain, or cough and headache, the physician is more likely to rely on GFs. This also happens when a patient presents with anxious-depressive symptoms that could mask an organic disease. GPs also mentioned the presence of GFs when a patient presents with symptoms that may suggest serious diseases, such as cancer or pulmonary embolism, even in the absence of 'red flags'. 
A serious pathology, and also slightly diffuse symptoms... With a pulmonary embolism, I remember seeing two patients and saying, "How did I get it right otherwise...?" (FG1/4)

By her aspect, how her character has changed the last months. She used to come alone, and she now comes with her daughter and her husband. Very worried...And I have the feeling that she may have a cancer. (FG3/20)

\section{Physician-related factors}

The GPs in our study thought that, although even young doctors and trainees have GFs, professional experience is a crucial factor in having and attaching importance to GFs. Most of the GPs declared that they have had GFs since the beginning of their medical careers. However, over the years, the memory of past experiences has made them more sensitive to GFs.

There's something that has turned on the light...a prior experience of having had similar events, or that reminds you of something. (FG1/9)

I think it's the years, although I'm not sure. The fact is, I don't know. When I began, I think I also had intuitions... (FG1/5)

Medical knowledge is also an important factor. GPs who know more have more confidence in their GFs. Both experience and medical knowledge develop in parallel with the credibility of GFs.

If you study a lot when you are R5 (first year after completing GP training) you can work it out. And if you don't study a lot, well, with 23 years of experience you have studied it in patients you have seen. In the end, it's knowledge. (FG3/17)

The GPs we interviewed did not think that a physician's gender had a significant influence on having and trusting GFs. Instead, they thought that a physician's personality, regardless of gender, plays a more decisive role.

There are some doctors who are more sensitive to gut feelings, and others who are less sensitive to gut feelings. Perhaps this is due to personality differences. (FG3/17)

\section{Context-related factors}

GFs may appear during regular consultation times, or during after-hours consultations. The GPs in our study reported that night consultations were more likely to generate GFs. Furthermore, consultations at night in a rural environment had a greater association with GFs.

It's not the same. Someone who comes in calmly at ten o'clock in the morning and someone who comes in at twelve o'clock at night...In the villages, normally if they call you at night it's trouble. They don't call unless there's a good reason. If they call you at three in the morning, it's because they really need help and you can start to run. (FG2/11)

The GPs reported having fewer GFs in emergency rooms due to the different approach to patient care in that environment. GPs work in emergency rooms in Spain, and many patients are referred by their GPs, so there is an initial 'filter' that indicates to the physician that there is a greater chance of serious disease.

I think that in a hospital, there are much fewer gut feelings, because they've gone through our "filter" and they arrive there, and everything is cut and dry...If you've reached here, it's because the suspicion is already there, and my job is to carry on the chain. (FG3/19)

Moreover, as a GP's workload grows, there are fewer GFs and it is more difficult to pay attention to them. Nevertheless, it is still possible to have GFs, and many doctors reported remembering having a sense of alarm in the middle of an overloaded working day.

If you're seeing a load of emergencies, you're going as fast as you can, and the GF threshold might rise. Some things get past you, which, with more calm, you might have realised. It's happened to me, seeing emergencies, about to close the health centre, five people waiting, and suddenly with one of them you say...(FG3/19)

Although GPs mainly focus on face-to-face consultations, we asked them about GFs in non-face-to-face consultations. They reported that it was also possible to have GFs from telephone consultations, especially if they knew the patient.

A call from a patient saying, "I'm out of breath", and you know they aren't out of breath. Or the other way round, just by hearing the voice you know you have to see the patient because something's wrong. It makes a difference if you know them. (FG3/20)

\section{Continuity of care}

Continuity of care is an important characteristic of primary care and also affects GFs. Knowing the patient, the social and family context, and the medical history and attitudes are crucial when attending a new episode. Spanish GPs in our study used knowledge provided by continuous care to quickly determine whether a patient had a serious disease.

You're lucky enough to have known this person from before. You already know them, and as soon as they come through the door, you begin to get some clues. $(\mathrm{FGl} / 4)$

(You know) a person who comes, who goes, their grandchild, the other, you've known them for fifteen years and you see they don't look right. But that's because you know them...That's one of the advantages of family medicine: continuity. (FG3/17) 


\section{Consequences of GFs}

The GPs in our study reported physical sensations when they had GFs. They hear bells ringing, they perceive a bad odour related to the situation, and they have bad bodily sensations.

This idea happened to me, and for a while I had a weird body sensation. (FG1/9)

There are people who, just when they enter the room, you say it smells like a neoplasia. And they still have not said anything. (FG1/4)

The GPs reported that a 'sense of alarm' is one of the tools used to initiate the diagnostic process. They sometimes have doubts and try to rationalise them, but most of the time they follow this 'sense of alarm'.

If there's something that doesn't fit, that patient is different to another one, and that's why I'm more concerned.

And I try to get to the bottom of it. (FG3/15)

When a sense of alarm is considered, the physician has a feeling of a job well done. When it is not considered, the GP remains restless.

Sometimes you have intuitions, but you don't always follow them. That is, sometimes you do, and when you follow them and you're right, that's great. And sometimes you don't, and you get left with a feeling like...you're left feeling angry. (FG1/9)

In these cases, the GPs take advantage of their closeness to the patient and the continuity of care, and try to be attentive to patient evolution.

Then you start looking. And if that patient doesn't come back, you look and see if they've had an emergency. Or you give them a call. I've done that, yes. The thing is, just the other day...I did that...(FG1/5)

A sense of reassurance helps doctors to balance their decisions, adopt a wait-and-see attitude and avoid excessive use of tests and treatments. The GPs usually felt comfortable following their sense of reassurance. Again, the possibility of further contact with the patient is a safety measure.

As you know, you can see them the next day or in three days' time, or even give them a call. You use this feeling of reassurance so as not to carry out tests you think are not appropriate. (FG1/2)

\section{Significance of GFs}

The GPs reported that GFs were important for certain diagnostic tasks.

I think we always attach value to these intuitions. (FG1/6)

In fact, GPs regarded GFs, especially the sense of reassurance, as a characteristic of primary care as opposed to hospital care. GPs are used to working with a high degree of uncertainty, and tend to avoid overtesting, because it may unnecessarily upset the patient and increase the cost of care.

We have to work like that, because if we don't, all forty of the people who come in through the door. If you do all the tests every day...This is the way we work in primary care. Making decisions depending on what you know about the patient. Today, they come in looking bad...It's got nothing to do with the way you work in a hospital, basing absolutely everything on tests. (FG1/9)

There are some doubts about the diagnostic accuracy of GFs. As aforementioned, GPs tend to follow their GFs, but they are also aware that their GFs may be wrong. When recalling previous successes and errors, there is a bias to better remember successes than failures.

That gut feelings exist, I believe they exist. But I can't tell you if I get it right very much. (FG3/18)

GPs who train residents reported that it was difficult to teach about the value of GFs. However, they also said they should try to teach residents about GFs. Afterwards, students and trainees may learn to pay more or less attention to their own GFs, depending on their personality. Young GPs agree that GFs are usually considered when discussing a case, even if not directly acknowledged.

I think the resident can be helped to develop them, and put them into practice. Not teach them or have them, because that does depend on your personality. (FG3/19)

The main way to help students and trainees take advantage of their GFs is by increasing the experience of GFs. GP trainers advocate the use of clinical cases for this purpose.

If you teach the resident from the start with clinical cases, you're increasing their experience. You have knowledge at the bottom of the "hard drive", and you use it unconsciously. With training based on clinical data, you put more and more information in there. (FG3/17)

\section{DISCUSSION}

The Spanish GPs in our study recognised the existence of GFs in their own diagnostic processes. In particular, they recognised two kinds of GFs: a sense of alarm, when something does not fit in the patient; and a sense of reassurance, the feeling that nothing serious will happen. The two factors with the strongest influence on the appearance of GFs are continuity of care in the patient-physician relationship, and amount of professional experience. The GPs in our study attached great value to their GFs, and considered them an important tool for carrying out their tasks, and even one of the main characteristics of working in a primary care setting. The GPs that we interviewed said that GFs cannot be 
directly taught during training, but the notion of GFs and their relevance can be transmitted to students and trainees. The GPs felt comfortable about considering their GFs during diagnosis, but were unsure of their accuracy. Thus, the GPs considered GFs as one of the tools available when deciding whether to begin a diagnostic process or to adopt a wait-and-see attitude. Figure 1 summarises the main discourses around GFs and how factors related to GFs appearance and the relevance given to them influence the diagnosis process.

We found no effect of gender or previous medical experience on the discourses of the GPs we examined. In fact, all the GPs in our study had experienced GFs during their work. Experienced GPs had more confidence in their GFs than less experienced GPs.

The results of our study are similar to those of previous research of GPs conducted in the Netherlands and France, in terms of recognition of the existence of GFs and their typology. Previous qualitative research reported the idea of GFs as the GP being worried (sense of alarm) or not (sense of reassurance) about a patient's prognosis, even in the absence of objective findings, and the role of GFs on whether to initiate the diagnostic process or a specific treatment. However, we found some small differences in Spanish GPs. Spanish GPs reported feeling cautious about the sense of reassurance provided by GFs, and although they usually followed their GFs, they remained alert to the resolution of the case. The GPs in our study referred to the sense of alarm from a GF more as a trigger for the diagnostic process than as a need for management. In this latter aspect, they are more similar to French GPs than Dutch GPs. As previously noted, the longer tradition of research and acceptance of GFs in the Netherlands than in France and Spain might explain these differences. ${ }^{23}$

Our use of a focus group study enabled us to select physicians with the characteristics we wanted. We found a wide consensus among GPs who had different years of experience, gender, teaching profiles and practice

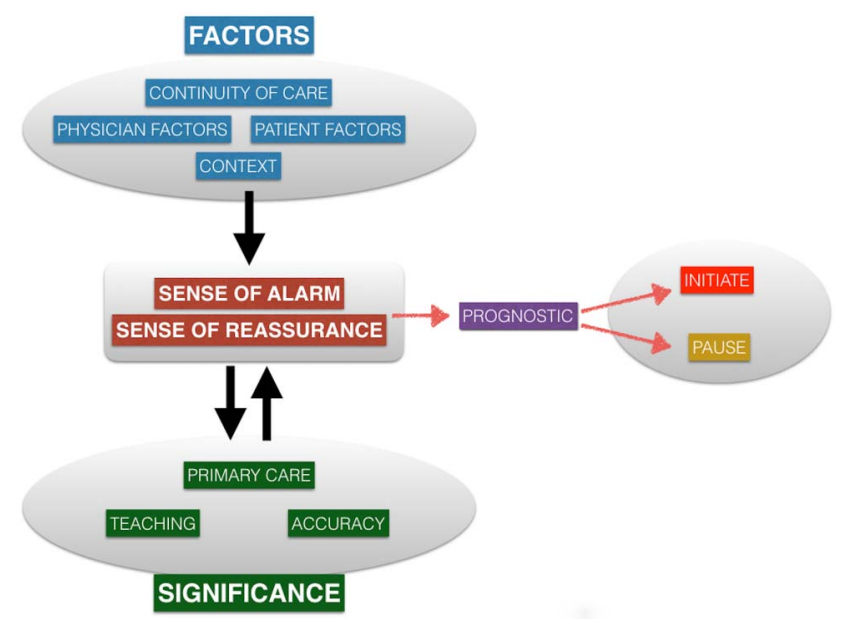

Figure 1 Factors and significance of gut feelings among Spanish general practitioners. locations. Saturation of information was quickly reached. Although our research was performed on the island of Majorca, where the languages of Spanish and Catalan coexist, we believe that the GPs interviewed in our study are representative of Spanish GPs. Physicians and patients use both languages in most practices. The organisation of medical practices and GP traineeship is very similar throughout Spain. There is no School of Medicine in Majorca, so GPs working in Majorca have all studied medicine elsewhere in Spain, and have the same medical culture as residents of the Spanish mainland. The GPs that we interviewed, and GPs in general, who work in the Majorca Primary Care Department, are born and raised in almost every region of Spain and Spanish-speaking South American countries.

The primary care environment has many uncertainties, and quick decisions are often necessary. These decisions must balance concerns about patient outcomes with avoiding unnecessary and expensive tests and treatments. Thus, experienced GPs may use their GFs as a tool to cope with the many different situations that have multiple possible outcomes and solutions. Concerning the issue of teaching GFs, the GPs in our study reported that it is important for students and residents to become familiar with the use of GFs in clinical practice. To increase their expertise and develop more accurate GFs, techniques such as clinical cases and scenarios may be used, as recommended in the literature on the teaching of intuition and expertise in medical training. ${ }^{30}$

The results of this study suggest the presence of GFs in Spanish doctors, and our findings are in agreement with studies of doctors from elsewhere in Europe. Future research on the GFs of doctors in Spain should seek to evaluate their diagnostic accuracy. Since Spanish GPs have a similar GF to the Dutch concept where the Gut Feeling Questionnaire originates, we can proceed to translate and make the linguistic validation of the Gut Feeling Questionnaire to Spanish, and use it to determine the presence and accuracy of GFs. In the few quantitative studies conducted on GPs' suspicion of cancer or serious illness after a consultation, the negative predictive value of suspicion was high and the positive predictive value was moderate, but these were comparable to the predictive values of the main 'red-flag' symptoms. ${ }^{15}$ Once we know the diagnostic accuracy of GFs, it may be possible to develop and assess teaching strategies.

\section{CONCLUSION}

Spanish GPs in our study recognised the presence of GFs during the diagnostic process. There were two main types of GFs: a sense of reassurance and a sense of alarm. The former is more common, but both are useful for discriminating between patients according to disease severity, an important goal in primary care. The GPs reported that clinical experience, duration of the patient relationship and frequency of patient contact were the main factors related to recognition of GFs. 
Author affiliations

${ }^{1}$ Majorca Primary Care Department, Trencadors Primary Health Centre, Llucmajor, Spain

${ }^{2}$ Majorca Primary Care Department, Research Unit, Palma de Mallorca, Spain

${ }^{3}$ Majorca Primary Care Department, Playa de Palma Primary Health Centre,

Palma de Mallorca, Spain

${ }^{4}$ Faculty of Health, Medicine and Life Sciences, Department of General Practice, Caphri School for Public Health and Primary Care, Maastricht University, Maastricht, The Netherlands

${ }^{5}$ Department of Primary and Interdisciplinary Care, University of Antwerp, Antwerp, Belgium

\section{Twitter Follow Bernardino Oliva @c_c_baxter}

Acknowledgements The authors are grateful to the GPs who formed the focus groups and the Health Centres that allowed use of their facilities.

Contributors The study was conceived and designed by BO, SM and ME with support from ES. Focus groups were organised by BO, SM and ME. BO, SM and $C G$ conducted the analysis. BO led the writing guided by SM and ME, with additional comments from ES. All authors read and approved the final manuscript.

Funding This work was supported by the Majorca Primary Care Department grant PI004/16. It also received funding support from the Network for Prevention and Health Promotion in Primary Care (redIAPP, RD12/0005/0011) cofinanced with European Union ERDF funds and the Carlos III Health Institute of the Ministry of Economy and Competitiveness.

Competing interests None declared.

Ethics approval The study was evaluated and approved by the Majorca Primary Care Department Research Committee.

Provenance and peer review Not commissioned; externally peer reviewed.

Data sharing statement Full transcripts of the focus groups and quotes and authorisation of the study are available by email from the corresponding author.

Open Access This is an Open Access article distributed in accordance with the Creative Commons Attribution Non Commercial (CC BY-NC 4.0) license, which permits others to distribute, remix, adapt, build upon this work noncommercially, and license their derivative works on different terms, provided the original work is properly cited and the use is non-commercial. See: http:// creativecommons.org/licenses/by-nc/4.0/

\section{REFERENCES}

1. Elstein AS, Schwarz A. Clinical problem solving and diagnostic decision making: selective review of the cognitive literature. BMJ 2002;324:729-32.

2. Klein JG. Five pitfalls in decisions about diagnosis and prescribing. BMJ 2005;330:781-3.

3. Reid MC, Lane DA, Feinstein AR. Academic calculations versus clinical judgments: practicing physicians' use of quantitative measures of test accuracy. Am J Med 1998;104:374-80.

4. Stolper E, Van De Wiel M, Van Royen P, et al. Gut feelings as a third track in general practitioners' diagnostic reasoning. J Gen Intern Med 2011;26:197-203.

5. Abernathy C, Hamm RM. Surgical intuition: what it is and how to get it. Hanley \& Belfus, 1995.
6. Dreyfus SE. The five-stage model of adult skill acquisition. Bull Sci Technol Soc 2004;24:177.

7. Kahneman D. A perspective on judgment and choice: mapping bounded rationality. Am Psychol 2003;58:697-720.

8. Kahneman D, Klein G. Conditions for intuitive expertise: a failure to disagree. Am Psychol 2009;64:515-26.

9. Naqvi N, Shiv B, Bechara A. The role of emotion in decision making: a cognitive neuroscience perspective. Curr Dir 2006;15:260-4.

10. Hull FM. The consultation process. In: Sheldon M, Brooke J, Rector A, eds. Decision-making in general practice. London: Macmillan Education UK, 1985:13-26.

11. Stolper E, van Royen P, Dinant GJ. The 'sense of alarm' ('gut feeling') in clinical practice. A survey among European general practitioners on recognition and expression. Eur J Gen Pract 2010;16:72-4.

12. Hams SP. A gut feeling? Intuition and critical care nursing. Intensive Crit Care Nursing 2000;16:310-18.

13. Mccutcheon HHI, Pincombe J. Intuition: an important tool in the practice of nursing. J Adv Nurs 2001;35:342-8.

14. Johansen M-L, Holtedahl KA, Rudebeck CE. How does the thought of cancer arise in a general practice consultation? Interviews with GPs. Scand J Prim Health Care 2012;30:135-40.

15. Hjertholm P, Moth G, Ingeman ML, et al. Predictive values of GPs' suspicion of serious disease: a population-based follow-up study. Br J Gen Pract 2014;64:346-53.

16. Iqbal IZ, Kara N, Hartley C. Gut instinct: a diagnostic tool? $J$ Laryngol Otol 2015;129:365-8.

17. Bruyninckx R, Van den Bruel A, Hannes K, et al. GPs' reasons for referral of patients with chest pain: a qualitative study. BMC Fam Pract 2009;10:55.

18. Van den Bruel $A$, Thompson M, Buntinx F, et al. Clinicians' gut feeling about serious infections in children: observational study. BMJ 2012;345:e6144.

19. Lykke K, Christensen P, Reventlow S. "This is not normal..."-signs that make the GP question the child's well-being. Fam Pract 2008;25:146-53.

20. Beglinger B, Rohacek M, Ackermann S, et al. Physician's first clinical impression of emergency department patients with nonspecific complaints is associated with morbidity and mortality. Medicine (Baltimore) 2015;94:e374.

21. Stolper $E$, van Bokhoven $M$, Houben $P$, et al. The diagnostic role of gut feelings in general practice. A focus group study of the concept and its determinants. BMC Fam Pract 2009;10:17.

22. Stolper $E$, Van Royen $P$, Van de Wiel M, et al. Consensus on gut feelings in general practice. BMC Fam Pract 2009a;10:66.

23. Le Reste JY, Coppens M, Barais M, et al. The transculturality of "gut feelings". Results from a French Delphi consensus survey. Eur J Gen Pract 2013;19:237-43.

24. Woolley A, Kostopoulou O. Clinical intuition in family medicine: more than first impressions. Ann Fam Med 2013;11:60-6.

25. Stolper CF, Van de Wiel MW, De Vet HC, et al. Family physicians' diagnostic gut feelings are measurable: construct validation of a questionnaire. BMC Fam Pract 2013;14:1.

26. Strauss A, Corbin JM. Basics of qualitative research: techniques and procedures for developing grounded theory. SAGE Publications, 1998.

27. Smithson J. Using and analyzing focus groups: limitations and possibilities. Int J Social Res Methodol 2000;3:103-11.

28. Ericsson KA. The influence of experience and deliberate practice on the development of superior expert performance. In: Ericsson KA, Charness N, Feltovich PJ, Hoffman RR Eds. The Cambridge handbook of expertise and expert performance. Cambridge University Press, 2006:683-704.

29. Fereday J, Muir-Cochrane E. Demonstrating rigor using thematic analysis: a hybrid approach of inductive and deductive coding and theme development. Int J Qual Methods 2008;5:4.

30. Klein G. The power of intuition: how to use your gut feelings to make better decisions at work. Random House, 2003. 